\title{
Development of canine C-reactive protein assays
}

\author{
Takaki Waritani ${ }^{*} \mathbb{D}$, Dawn Cutler and Jessica Chang
}

\begin{abstract}
C-reactive protein (CRP), which is released during tissue damage and inflammation, is a useful nonspecific inflammatory marker in both human and veterinary clinical practice. Veterinarians have often used human CRP assays to analyze samples from canine patients, but cross-reactivities between the species affect assay sensitivity and reliability, leading to inaccurate inflammation assessment. To improve the efficiency of inflammation assessment, we developed a canine CRP detection enzyme-linked immunosorbent assay (ELISA) for quantitative analysis and an immunochromatography assay (ICA) for semiquantitative point-of-care (POC) analysis. The ELISA demonstrated an assay detection limit of $0.5 \mathrm{ng} / \mathrm{mL}$, quantitative linear assay range of $1.6-100 \mathrm{ng} / \mathrm{mL}$, and intra- and inter-assay coefficient of variations of 0.7 to $10.0 \%$ and 6.0 to $9.0 \%$, respectively; the recovery rates of samples spiked with purified canine CRP were 105 to $109 \%$, and the parallelism assessments were 82.7 to $104.4 \%$. The correlation between the CRP level results obtained with the ELISA and those of a currently available quantitative POC assay was 0.907 with the regression formula of $y=0.55 x+0.05$. In addition, the ICA requires only $5 \mu \mathrm{L}$ samples and a 10-min assay time, and clearly distinguished positive, weak positive, and negative samples $(P<0.001)$ at an approximately $5-10 \mu \mathrm{g} / \mathrm{mL}$ cut-off value. The developed canine CRP ELISA and ICA showed reliable assay results and a high correlation with a commercially available POC assay in clinical use. The ICA can be a useful canine CRP screening test for diagnostic purposes in veterinary clinics.
\end{abstract}

Keywords: C-reactive protein, Dogs, Enzyme-linked immunosorbent assay, Immunochromatography assay, Inflammation

\section{Findings}

The level of canine serum C-reactive protein (CRP), an acute-phase protein released during tissue damage and inflammation, is elevated 100 - to 1000 -fold in surgical trauma, irritation, and inflammatory diseases, including pyometra, panniculitis, acute pancreatitis, polyarthritis, septic arthritis, and hemangiosarcoma [1-3]. The serum level dynamics indicate that canine CRP is a useful, nonspecific, sensitive inflammatory marker $[1,2,4]$.

The canine serum CRP level is generally measured with human diagnostic CRP immunoassays, including automated biochemical analyzers [5], enzyme-linked

\footnotetext{
*Correspondence: twaritani@chondrex.com
}

Chondrex, Inc., 2607 151 st Place North East Redmond, Washington 98052, USA immunosorbent assays (ELISAs) [6, 7] and latex agglutination tests $[3,8]$. However, due to the poor cross-reactivity of anti-human CRP antibodies with canine CRP, some of these human CRP assays demonstrate relatively unreliable assay results and mislead inflammation assessment. To achieve more reliable results, several commercial canine CRP-specific assays have been introduced to the market. However, technical improvements are needed to decrease between-run imprecision $[9,10]$.

Canine CRP ELISAs can be useful for routine checkups but are not appropriate as a rapid test for daily clinical use because of the time and labor required. Recently, commercially available canine CRP point-of-care (POC) assay kits, including quantitative immunoassays using analyzers $[11,12]$ and semiqualitative immunochromatography assays (ICAs) [10], have been developed. Unfortunately, 
these kits may still require investigation as they tend to yield imprecise results [13].

The aim of this study was to develop a highly reliable canine CRP ELISA and ICA using anti-canine CRP monoclonal antibodies (mAbs). These assays were validated using clinical samples and compared with a commercially available POC assay (Laser CRP-2 Analyzer from Arrows Co., Ltd, Osaka, Japan) (Laser).

MAbs against canine CRP were developed by cell hybridization of SP2/0-Ag4 cells and splenocytes from $\mathrm{BALB} / \mathrm{c}$ mice (Envigo, Indianapolis, IN, USA) immunized with purified canine CRP (LEE Biosolutions, Maryland Heights, MO, USA). Hybridomas producing anti-CRP mAbs were screened using an indirect canine CRP ELISA and then cloned by the limiting dilution method. The specificity of the anti-canine CRP mAbs was confirmed by western blot analysis (data not shown). The mAbs produced by hybridomas were purified by Protein $G$ affinity chromatography (GE Healthcare Systems, Chicago, IL, USA) from culture medium collected with a miniPERM culture system (Sarstedt, Newton, SC, USA).

We developed a canine CRP ELISA employing a one-step sandwich assay system using purified canine $\mathrm{CRP}$ and two anti-canine CRP mAbs. Briefly, the mAb $4 \mathrm{D} 3 \mathrm{C} 1$ was diluted in $100 \mu \mathrm{L}$ of $0.05 \mathrm{M}$ phosphate-buffered saline buffer, $\mathrm{pH}$ 7.4 (PBS), added to each well of a 96-well ELISA plate and incubated at $4{ }^{\circ} \mathrm{C}$ overnight. After washing the plates with PBS containing $0.05 \%$ Tween 20 (PBST), $50 \mu \mathrm{L}$ of the mAb 3B4D3 conjugated with horseradish peroxidase in PBS containing $1 \%$ bovine serum albumin (BSA) (BSA/PBS) and $50 \mu \mathrm{L}$ of canine CRP standards or diluted canine serum samples (1:1000 or higher dilution) in BSA/PBS were added to the wells. The plate was incubated for $1 \mathrm{~h}$ at room temperature (i.e. around $25{ }^{\circ} \mathrm{C}$ ). After washing the plates with PBST, color was developed at room temperature for $25 \mathrm{~min}$ by adding $100 \mu \mathrm{L}$ of 3,3',5,5'-tetramethylbenzidine solution (MP Biomedicals, Santa Ana, CA, USA). After adding $50 \mu \mathrm{L}$ of $2 \mathrm{~N}$ sulfuric acid to stop the enzymatic reaction, absorbance values were measured at $450 \mathrm{~nm}$. The CRP levels in samples were calculated using linear regression based on a standard curve in Microsoft Excel and multiplied by the corresponding dilution factor to obtain true values $(\mu \mathrm{g} / \mathrm{mL})$.

A canine CRP ICA was developed by modifying a previously described technique [14]. Briefly, the kit was composed of a high-flow nitrocellulose membrane strip (MilliporeSigma, Burlington, MS, USA) prebound with the $\mathrm{mAb} 4 \mathrm{D} 3 \mathrm{C} 1$ and anti-mouse IgG polyclonal antibodies (Southern Biotech, Birmingham, AL, USA) as a sample line and a control line, respectively, a glass filter strip (MilliporeSigma) absorbed with mAb 3B4D3 conjugated with colloidal golds, cellulose papers (MilliporeSigma), a backing sheet (DCN Diagnostics, Carlsbad, CA, USA), and a device case (DCN Diagnostics). The assay was performed by loading $5 \mu \mathrm{L}$ of undiluted canine serum followed by $100 \mu \mathrm{L}$ of BSA/PBS containing $0.1 \%$ Tween 20 in the sample well of the device. If both the red sample line and control line appeared in the test window of the device after $10 \mathrm{~min}$, the assay was deemed to have a positive result, which was further distinguished as positive with a dark sample line and weak positive with a light sample line. If the sample line did not appear, the assay was deemed to have a negative result (Fig. 1).

The developed ELISA demonstrated an assay detection limit of $0.5 \mathrm{ng} / \mathrm{mL}$, and a quantitative linear assay range of $1.6-100 \mathrm{ng} / \mathrm{mL}$ for the standard curve $(\mathrm{R}=0.996)$ (Additional file 1). The intra-assay and inter-assay coefficient of variations were 0.7 to $10.0 \%$ and 6.0 to $9.0 \%$, respectively, with a range of 3.2 to $50 \mathrm{ng} / \mathrm{mL}$ of CRP in serum samples diluted with BSA/PBS $(n=3)$ (Additional file 2). The spike tests in which three serum samples were spiked with known amounts of purified CRP demonstrated recovery rates ranging from 105 to $109 \%$ (Additional file 2). The parallelism assessments using four samples demonstrated recovery rates ranging from 82.7 to $104.4 \%$ in several sample dilutions (Additional file 3).

The canine serum test samples consisted of 16 samples from healthy blood donors as healthy control dogs (control group) and 38 samples from client-owned dogs presented to the Research Institute of Biosciences, Azabu University, Sagamihara, Japan as diseased dogs (patient group). All experimental protocols were approved by the Animal Experiment Committee of Azabu University.

The CRP levels of the patient group were evaluated using both our ELISA and the Laser commercial POC assay at Azabu University (Additional file 4). Undiluted serum samples were applied to the Laser assay, but serum samples diluted to 1:1000 or higher with BSA/PBS were used for our ELISA because of its high assay sensitivity. Three of the 38 samples assayed were omitted from this analysis because their serum CRP levels were out of the Laser's quantitative assay range. The correlation between the CRP levels obtained with our ELISA and those obtained with the Laser assay was 0.907 with the regression formula of $y=0.55 x+0.05$ (Fig. 2). The slope of 0.55 suggests that our ELISA obtained approximately 55\% lower CRP levels than the Laser assay. Since the Laser assay employs a CRP positive cut-off value of $10 \mu \mathrm{g} / \mathrm{mL}$, our ELISA would have an equivalent positive cut-off value of $5.5 \mu \mathrm{g} / \mathrm{mL}$. The difference may be due to the different standard preparation and validation methods of the two assays. Two sample results (sample \#15 and \#21) showed discrepancies between our ELISA and the Laser assay (Additional file 4). Generally, ELISAs tend to produce more reliable results than POC assays because of 


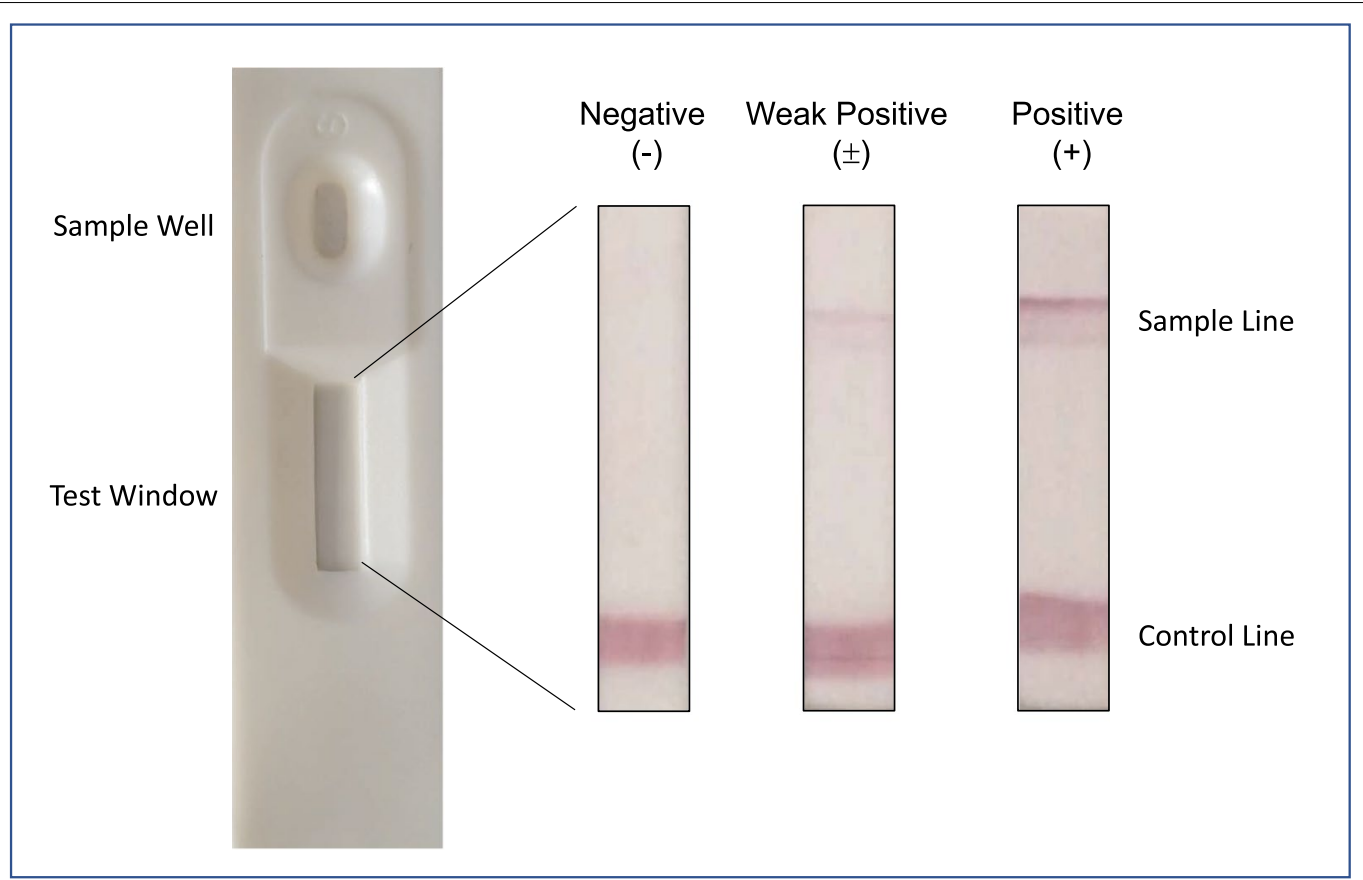

Fig. 1 Assay results for the immunochromatography assay. Undiluted canine serum ( $5 \mu \mathrm{L}$ ) and $100 \mu \mathrm{L}$ of BSA/PBS containing $0.1 \%$ Tween 20 were loaded in the sample well on the device. After $10 \mathrm{~min}$, the assay results were determined: negative $(-)$, weak positive $( \pm)$, or positive $(+)$. Positive and weak positive results are considered CRP positive

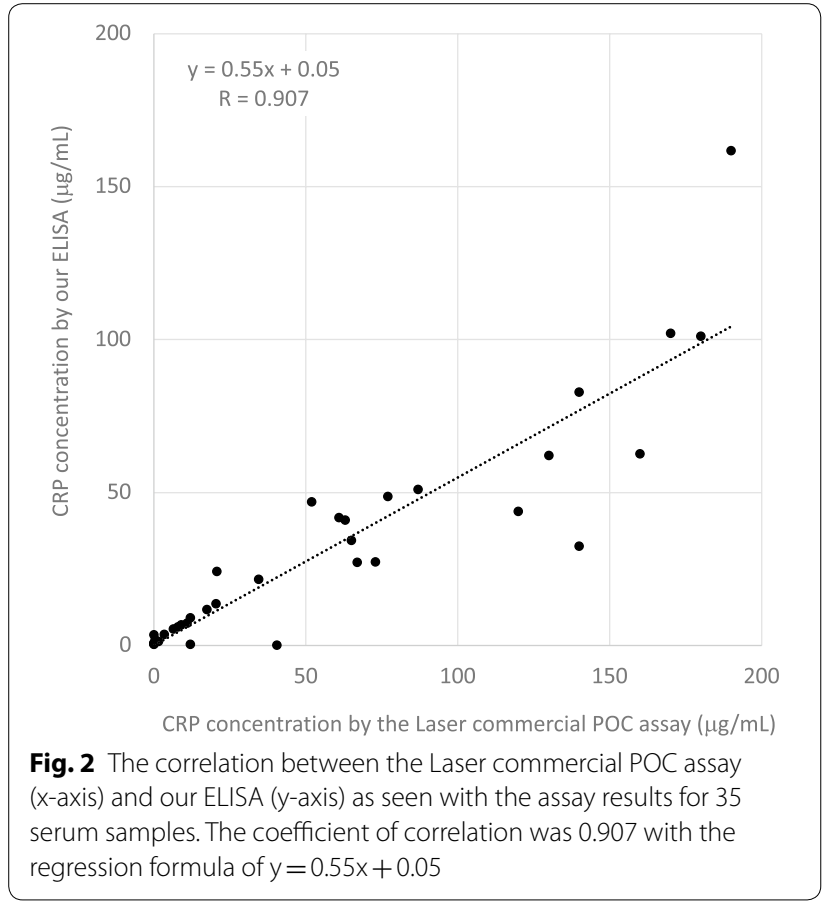

the ELISA's multiple assay steps, such as washing steps. This may indicate that more investigation is required to obtain higher precise results with POC assays [13].
The mean value ( \pm standard deviation: $S D$ ) of serum CRP assayed by our ELISA in the control group was $1.1 \pm 1.3 \mu \mathrm{g} / \mathrm{mL}$ (range 0.1 to $4.6 \mu \mathrm{g} / \mathrm{mL}$ ), which correlated well with the findings of previous reports [5-7]. While the mean value $( \pm \mathrm{SD})$ of serum CRP in the patient group was $40 \pm 53.4 \mu \mathrm{g} / \mathrm{mL}$ (range 0.1 to $259.3 \mu \mathrm{g} / \mathrm{mL}$ ) (Additional file 5). The control group samples showed a lower range of serum CRP levels, while the patient group samples showed a very wide range of serum CRP levels. Interestingly, ten samples in the patient group had serum CRP levels lower than $4.6 \mu \mathrm{g} / \mathrm{mL}$, at which point the range overlapped with the serum CRP levels in the control group. This indicated that the serum CRP level depends on the inflammatory condition in the individual dogs. However, it also suggested that serum CRP levels higher than those seen in healthy control dogs obviously indicate higher levels of inflammation. While the evaluation of serum CRP levels must be considered in the context of the clinical disease condition, we suggest that CRP levels assayed by our ELISA can distinguish noninflammatory and inflammatory conditions using approximately $5 \mu \mathrm{g} / \mathrm{mL}$ as the cut-off value (mean $+3 \mathrm{SD}$ : $1.1+3 \times 1.3 \mu \mathrm{g} / \mathrm{mL}$ ) based on the results for the control group, and equivalent cut-off values $(5.5 \mu \mathrm{g} / \mathrm{mL})$ were seen with the Laser assay in this study and in previous reports $[11,12]$. 
Canine serum samples with known CRP levels evaluated by our ELISA were assayed using our ICA. The ICA showed negative results for serum CRP levels lower than $11.7 \mu \mathrm{g} / \mathrm{mL}$ (mean \pm SD: $2.3 \pm 2.9 \mu \mathrm{g} / \mathrm{mL}$ ) except for in one sample $(6.0 \mu \mathrm{g} / \mathrm{mL})$, weak positive results between 6.0 and $40.2 \mu \mathrm{g} / \mathrm{mL}$ (mean \pm SD: $20.4 \pm 14.7 \mu \mathrm{g} / \mathrm{mL}$ ), and positive results for levels higher than $24.1 \mu \mathrm{g} / \mathrm{mL}$ (mean \pm SD: $72.9 \pm 59.0 \mu \mathrm{g} / \mathrm{mL}$ ) (Fig. 3, Additional file 5). There were significant differences $(\mathrm{P}<0.001)$ in serum $C R P$ levels between the three individual assay results (Fig. 3). Because the ICA produced negative results for samples with a level lower than $11.7 \mu \mathrm{g} / \mathrm{mL}$ and weak positive results for samples with a level higher than $6.0 \mu \mathrm{g} / \mathrm{mL}$, the cut-off value of the ICA was suggested to be approximately $5-10 \mu \mathrm{g} / \mathrm{mL}$, which is comparable to the cut-off values of commercial assays $[11,12]$. The cut-off value of the ICA was confirmed using diluted serum samples known CRP levels as approximately $5 \mu \mathrm{g} / \mathrm{mL}$ agreed with the results of clinical samples, producing negative results for samples with a level lower than $4.3 \mu \mathrm{g} / \mathrm{mL}$ and positive results for those with a level higher than $4.4 \mu \mathrm{g} / \mathrm{mL}$ (Table 1). Negative results in our ICA were obtained for the two samples (sample \#15 and \#21) with an observed discrepancy in results between our ELISA and the Laser assay and were agreed with our ELISA results (Additional files 4 and 5).

These studies demonstrate that our ELISA shows good correlations with a commercially available POC assay and

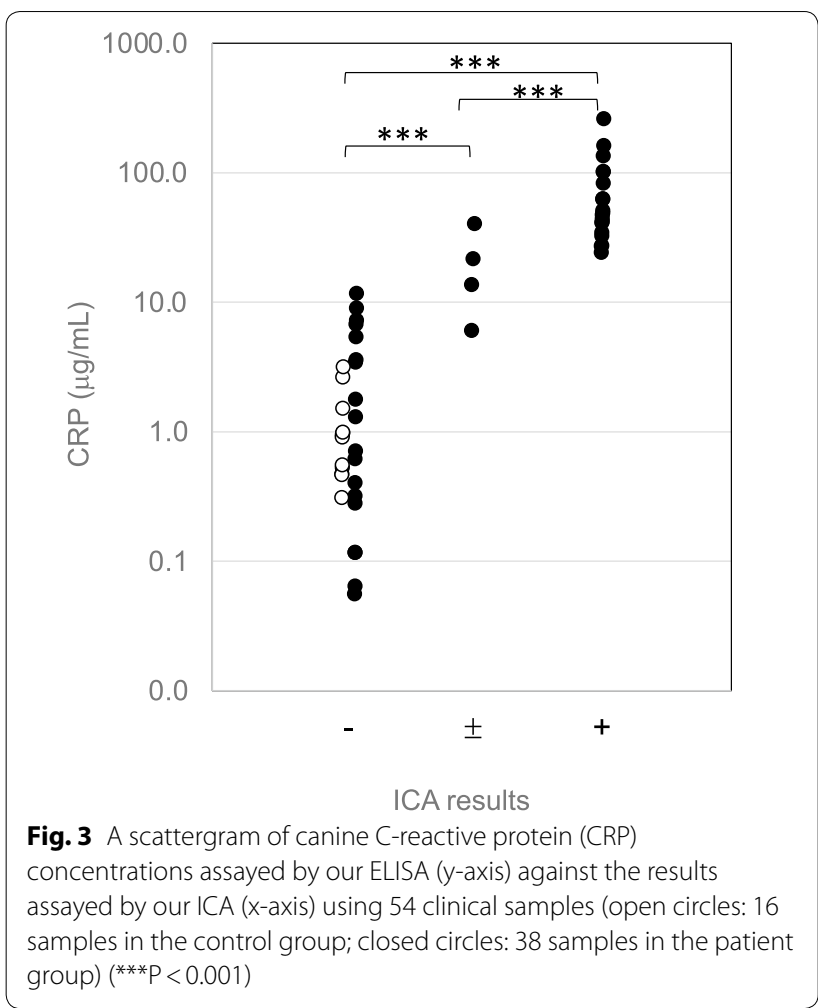

Table 1 Precision and accuracy tests of the canine CRP ICA using serial dilutions of four serum samples. The CRP levels were determined with our ELISA at a 1:1000 sample dilution. ICA results: - , negative; \pm , weak positive; and +, positive

\begin{tabular}{|c|c|c|c|}
\hline Sample \# & Dilution & CRP $(\mu \mathrm{g} / \mathrm{mL})$ & ICA results \\
\hline \multirow[t]{6}{*}{ S1 } & $1: 2$ & 38.2 & + \\
\hline & $1: 4$ & 19.0 & + \\
\hline & $1: 8$ & 9.3 & + \\
\hline & $1: 16$ & 4.4 & \pm \\
\hline & $1: 32$ & 2.0 & - \\
\hline & $1: 64$ & 0.9 & - \\
\hline \multirow[t]{5}{*}{ S2 } & $1: 2$ & 29.4 & + \\
\hline & $1: 4$ & 14.4 & + \\
\hline & $1: 8$ & 7.0 & \pm \\
\hline & $1: 16$ & 3.5 & - \\
\hline & $1: 32$ & 1.6 & - \\
\hline \multirow[t]{4}{*}{ S3 } & $1: 2$ & 18.9 & + \\
\hline & $1: 4$ & 9.1 & \pm \\
\hline & $1: 8$ & 4.3 & - \\
\hline & $1: 16$ & 2.1 & - \\
\hline \multirow[t]{6}{*}{ S4 } & $1: 2$ & 56.6 & + \\
\hline & $1: 4$ & 29.2 & + \\
\hline & $1: 8$ & 14.8 & + \\
\hline & $1: 16$ & 6.9 & \pm \\
\hline & $1: 32$ & 3.4 & - \\
\hline & $1: 64$ & 1.7 & - \\
\hline
\end{tabular}

our ICA. The ICA can be used as an alternative diagnostic tool to evaluate the inflammation status in veterinary clinics that do not have analyzers.

In veterinary clinics, diagnostic kits commonly require blood, serum, and/or plasma test samples. However, unlike in human clinics, drawing blood from animals usually requires either restraints with a risk of animal bites for clinic workers or anesthesia with a risk for the patient. Alternatively, in human medicine, saliva and urine samples have been traditionally used for diagnostic test purposes. Saliva sample preparation is especially advantageous due to the collection method being noninvasive, nonstressful, and easy for patients.

Recently, it was reported that the CRP levels in saliva are approximately $1 / 100$ levels of those in the serum, but salivary CRP levels correlate with serum CRP levels, and diseased dogs tend to express significantly higher salivary CRP levels than healthy dogs [9]. For detecting very low levels of salivary CRP, a higher sensitivity assay is required. This study suggests that our ELISA may be able to determine salivary CRP levels at an approximately 1:10 sample dilution instead of the 1:1000 dilution used for serum CRP analysis. The ICA was developed with the 
intent of reducing assay sensitivity during assay optimization to adjust an appropriate cut-off value for the serum CRP assay. Indeed, development of an ICA for saliva samples requires further assay condition optimization for determining ideal sample volumes, mAb concentrations, assay procedures, and assay time to achieve a sufficient assay sensitivity. We believe that a canine salivary CRP ICA would potentially be a convenient diagnostic tool in veterinary clinics.

Our newly developed canine CRP ELISA and ICA showed reliable assay results and a high correlation with a commercially available POC assay in clinical use. The ICA can be a useful canine CRP screening test for diagnostic purposes in veterinary clinics. In addition, the pair of mAbs used in our assays can be adapted for quantitative POC assays in the future.

\section{Supplementary information}

Supplementary information accompanies this paper at https://doi. org/10.1186/s13028-020-00549-9.

Additional file 1. A standard curve for canine C-reactive protein (CRP) concentrations from 1.6 to $100 \mathrm{ng} / \mathrm{mL}$ generated with our one-step sandwich ELISA. Purified canine CRP was quantitated by using a combination of two mAbs: 4D3C1 as the capture antibody and 3B4D3 conjugated with horseradish peroxidase as the detection antibody.

Additional file 2. Precision tests using three CRP levels in our ELISA. Repeatability studies (intra- and inter-assay variations) using diluted serum samples with three CRP levels in BSA/PBS were performed in triplicate in each assay and on three different occasions. The spike tests were performed using three diluted serum samples spiked with known amounts of purified CRP. The results are expressed as the average recovery rates determined by dividing the observed CRP levels by the expected CRP levels.

Additional file 3. Parallelism assessments of our ELISA using four serially diluted serum samples. Each sample was serially diluted with BSA/PBS. The results are expressed as the recovery rates determined by dividing the observed CRP levels by the expected CRP levels.

Additional file 4. CRP levels of 38 samples in the patient group determined by our ELISA and the Laser commercial POC assay.

Additional file 5. CRP levels of 16 samples in the control group and 38 samples in the patient group determined by our ELISA and assay results for our ICA. ICA results; -: negative; \pm : weak positive; + : positive.

\section{Abbreviations}

BSA: Bovine serum albumin; CRP: c-reactive protein; ELISA: Enzyme linked immunosorbent assay; HRP: Horseradish peroxidase; ICA: Immunochromatography test; mAbs: Monoclonal antibodies; POC: Point-of-care.

\section{Acknowledgements}

The authors gratefully acknowledge all of the employees at Chondrex, Inc. for their valuable support. Without their kind cooperation, this study would have been impossible to conduct.

\section{Authors' contributions}

TW conducted the experiment, performed statistical analysis, and prepared the manuscript. JC performed hybridoma development and assisted in manuscript review. DC performed animal care and mAb manufacturing. All authors read and approved of the final manuscript.

\section{Funding}

Not applicable

\section{Availability of data and materials}

The datasets generated and analyzed during the current study are available from the corresponding author upon requests.

\section{Ethics approval and consent to participate}

Sample collection protocols were approved by the Animal Experiment Committee of Azabu University.

\section{Consent for publication}

Not applicable.

\section{Competing interests}

TW, DC and JC declare that they received salary support from Chondrex, Inc. The organizations which provided support in the form of salaries for the authors (TW, DC, and JC) did not play any roles in the study design, data collection and analysis, decision to publish, or preparation of this manuscript. This does not alter our adherence to Acta Veterinaria Scandinavica policies on sharing data and materials.

Received: 8 February 2020 Accepted: 31 August 2020

Published online: 07 September 2020

\section{References}

1. Conner JG, Eckersall PD, Ferguson J, Douglas TA. Acute phase response in the dog following surgical trauma. Res Vet Sci. 1988:45:107-10.

2. Hillstrom A, Bylin J, Hagman R, Bjorhall K, Tvedten H, Konigsson K, et al. Measurement of serum C-reactive protein concentration for discriminating between suppurative arthritis and osteoarthritis in dogs. BMC Vet Res. 2016;12:240.

3. Yamamoto S, Shida T, Okimura T, Otabe K, Honda M, et al. Determination of $C$-reactive protein in serum and plasma from healthy dogs and dogs with pneumonia by ELISA and slide reversed passive latex agglutination test. Vet Q. 1994;16:74-7.

4. Nakamura M, Takahashi M, Ohno K, Koshino A, Nakashima K, et al. C-reactive protein concentration in dogs with various diseases. J Vet Med Sci. 2008:70:127-31.

5. Eckersall PD, Conner JG, Harvie J. An immunoturbidimetric assay for canine C-reactive protein. Vet Res Commun. 1991;15:17-24

6. Eckersall PD, Conner JG, Parton H. An enzyme-linked immunosorbent assay for canine C-reactive protein. Vet Rec. 1989;124:490-1.

7. Rikihisa Y, Yamamoto S, Kwak I, Iqbal Z, Kociba G, et al. C-reactive protein and alpha 1-acid glycoprotein levels in dogs infected with Ehrlichia canis. J Clin Microbiol. 1994:32:912-7.

8. Tagata K, Yokoyama S, Ginbo T, Honda M, Okimura T, et al. Quantitative capillary reversed passive latex agg lutination test for $\mathrm{C}$-reactive protein (CRP) in the dog. Vet Res Commun. 1996;20:21-30.

9. Parra MD, Tecles F, Martinez-Subiela S, Ceron JJ. C-reactive protein measurement in canine saliva. J Vet Diagn Invest. 2005;17:139-44.

10. Kjelgaard-Hansen M, Jensen AL, Kristensen AT. Evaluation of a commercially available human C-reactive protein (CRP) turbidometric immunoassay for determination of canine serum CRP concentration. Vet Clin Pathol. 2003;32:81-7.

11. Hindenberg S, Kessler M, Zielinsky S, Langenstein J, Moritz A, et al. Evaluation of a novel quantitative canine species-specific point-of-care assay for C-reactive protein. BMC Vet Res. 2018;14:99.

12. Jasensky AK, Klenner S, Einspanier R, Kohn B. Evaluation of three different point-of-care tests for quantitative measurement of canine C-reactive protein. Vet Clin Pathol. 2015:44:205-14.

13. McGrotty YL, Knottenbelt CM, Ramsey IK, Reid SW, Eckersall PD. Evaluation of a rapid assay for canine C-reactive protein. Vet Rec. 2004;154:175-6.

14. Waritani $T$, Onda M, Okuno $Y$, Neo $S$, Furuichi $M$, et al. One-step immunochromatography assay for detection of high-level canine serum trypsin-like immunoreactivity. JVet Med Sci. 2007:69:669-71.

\section{Publisher's Note}

Springer Nature remains neutral with regard to jurisdictional claims in published maps and institutional affiliations. 